\title{
Application of 3D Printing Teaching Aids in Mechanical Drawing Class
}

\author{
Jin-ru MA* \\ Beijing Polytechnic \\ Beijing China \\ mjr0425@126.com
}

\author{
Hui YU, Rui-can HAO and Hua-gang LIU \\ Beijing Polytechnic \\ Beijing China
}

\begin{abstract}
Mechanical Drawing is a required professional foundation course for students majoring in mechanical specialties. However, as students don't have actual engineering practice ability and are with poor spatial imagination, it is difficult for them to image plane figures as 3D shapes and to establish the concept of space. Therefore, teaching aids are necessary for them. As teaching aids output is little on the market, some of them have complicated structures and therefore need customizing. Their high production cost leads to a high price. As a result, some schools cannot afford them. With the development and progress of IT, 3D printing technology is applied in teaching aid manufacturing, making manufacturing cost low and manufacturing fast and convenient. The application of 3D printing technology in Mechanical Drawing class will not only help students establish spatial imagination, but also stimulate their study interests.
\end{abstract}

Keywords—mechanical drawing; teaching aid; 3D printing

\section{INTRODUCTION}

Mechanical Drawing is a required professional foundation course for students majoring in mechanical specialties. The core content of this class is to learn drawing threeview drawing according to a given object, and image a 3D object according to the given three-view drawing. As students have no actual engineering practice and poor spatial imagination, it is difficult for them to image plane figures as 3D shapes and to establish the concept of space. They usually feel worried and teachers often feel tired to teach them. How should this obstacle be settled? We try to manufacture teaching aids that students can refer to from "geometry instancing" [1]. With the constant improvement of 3D printing technology and decrease in printing costs, it becomes possible to apply $3 \mathrm{D}$ printing models in class teaching. 3D printing technology can be used to print teaching aids of appropriate size and light weight, which can be easily used for demonstration and disassembled without location restrictions. One thing that we should do is to select software UG that can be easily operated, establish a model with geometric solids (cylinder, cone and ball) and print the model from 3D printer. When it is finally presented in class, students can study theories giving reference to this 3D printing physical model, helping them establish the sense of 3D space, and understand theoretical knowledge more thoroughly. 3D printing models can also liven up class atmosphere and improve study results.
Besides, 3D printing technology can be used to print various types of machine parts (such as reducer), which can help students understand equipment principle and structure more easily in class, deepen their impression, and further improve class teaching efficiency. In this paper, 3D printing teaching aids are applied in Mechanical Drawing class teaching, which, as a result, improves teaching mode and enhances teaching efficiency and teaching results. [2]

\section{INTRODUCTION TO 3D PRINTING TECHNOLOGY}

3D Printers, also called Rapid Prototyping Manufacturing (RPM), or additive manufacturing. Rapid Prototyping Manufacturing born in late 1980s, is a high tech manufacturing technology based on material increase manufacturing, and a technology that can be used to create any shape, without traditional tools, fixtures and machine beds, and manufacture physical models with prototyping equipment in the form of material increase, according to the $3 \mathrm{D}$ model data of a part or an object. It is therefore thought one of the major achievements for the recent 20 years in manufacturing field.

Due to different prototyping materials, prototyping principles and system characteristics, different types of Rapid Prototyping Manufacturing systems are formed, all of which, however, follow the basic principle: layered manufacturing and overlapping layer by layer. Rapid Prototyping Manufacturing system is like a "Stereo printer", and that is where its name comes from. The name "3D printer". The process of rapid prototyping in Fig. 1

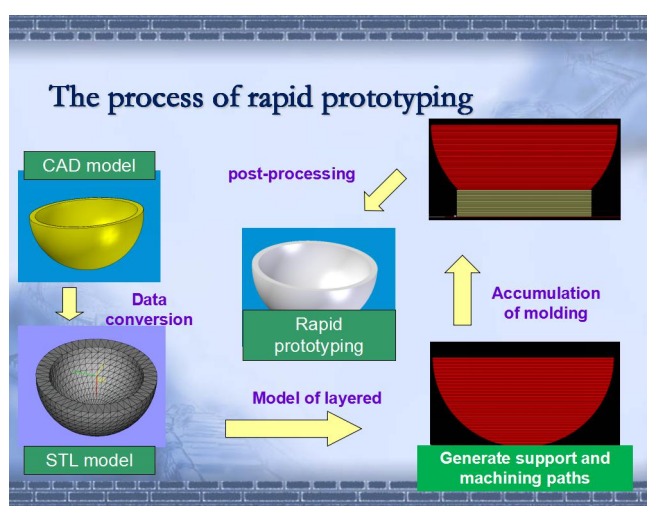

Fig. 1. The process of rapid prototyping

Thanks to the fund and support from the general program of Beijing Municipal Edu-cation Commission (NO.KM201910858005). 
At present, 3D printing technology is mainly divided into SLS (Selective Laser Sintering), SLA (Stereo lithography Appearance) and FDM ((Fused Deposition Modeling). Process classification in Fig. 2.

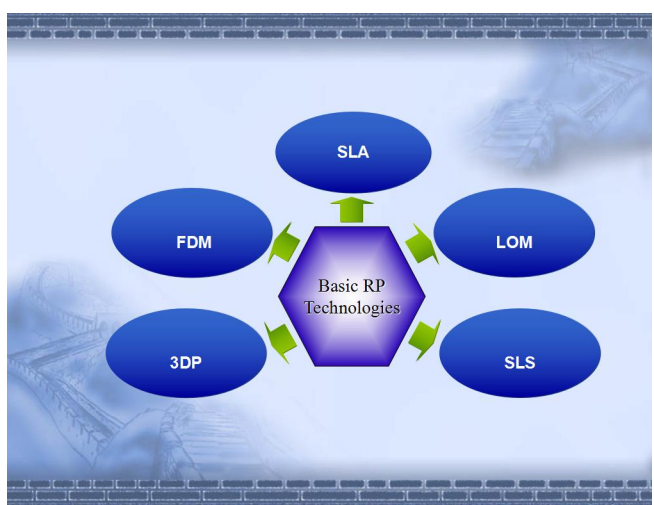

Fig. 2. Process classification

SLS sinters material powder under highintensity laser illumination selectively to obtain the cross-section of part, and then generate the part in the needed shape through overlapping layer by layer. There is a wide range of materials applying to SLS, such as nylon, was ABS, metal and ceramic powder.

Also called stereo lithography, stereo printing or laser prototyping, SLA is a kind of RPM technology that is invented the earliest, studied the most thoroughly, applied the widest and applied the most proficiently in the world and used to photocure RPM materials to the liquid photosensitive resin.

According to FDM, thermoplastic polymer material is heated to make it melt into wires, and then half flowing material is squeezed according to the layered data control path with hot spray nozzle; the material then is deposited at the specified position for consolidation forming and deposition layer by lawyer in order to form a whole prototype or part. The technology is also known as fused deposition method and melted extrusion molding. FDM refers to a kind of method for heating and melting wire materials to mold them not using laser as molding energy. The materials used are ABS and PLA[2].

After taking cost and the convenience of operation site into consideration, 3D printing teaching aids in this Paper are all printed with FDM after considering the above three processes synthetically. FDM uses ABS and PLA as printing material. ABS is widely used in industry for its high intensity, lightweight, large surface hardness, smoothness, easy cleaning and handling, stable size and good creep resistance. However, it generates big smell after it is heated and melted in using process. It is used less frequently in order to protect students' physical health. PLA is a new biobased and renewable biological degradation material. Made from the starch extracted from renewable plant materials (such as corn, cassava), it generates carbon dioxide and water in the end, bringing no pollution to the environment. It helps protect the environment and is thus universally acknowledged as a kind of environmentally friendly material. Therefore, PLA is selected as printing material to manufacture teaching aids with FDM.

\section{APPLICATION}

A. The assistance of $3 D$ printing teaching aids in the theoretical knowledge study of students in Mechanical Drawing course

1) Models help build students' spatial imagination.

Models of basic shapes, such as cone, cylinder and ball, made with 3D printers help students build their spatial imagination. If teachers just explain how to draw the projections of basic geometries, students will learn how to draw them but they cannot imagine what the geometries really are in life when seeing plane figures. These models give an intuitive guide to students and stimulate their study interest.

2) Teaching aids help students analyze the projection of assembly.

It is very hard to analyze the projection of an assembly in drawing class. But 3D printing models help students image the shape of the three-view drawing of the assembly, guide them to draw the assembly and its three-view drawing, so that they can master the methods and steps to read the three-view drawing of the assembly

3) Helping students recognize detail drawing

Models of physical parts enable students to make clear what the part is at a glance, and to accept model and pattern comparison more easily, realizing ideal teaching results[3].

4) Models help students understand the working principle and structure of assembly parts.

3D Printing can be used to manufacture the miniatures of complicated machine parts to help students learn about their structure and working principle in part assembly process, so that they are able to understand assembly relationship and complete machine part assembly drawing easily.

\section{B. The manufacturing process of $3 D$ printing teaching aids}

helps students study Mechanical Drawing courses

3D Printing has a quick molding speed. It finishes printing small models within 1 or 2 hours. Therefore, to ask students to print teaching aids on their own helps establish their spatial imagination in Mechanical Drawing class. 3D printing can be divided into 4 steps: modeling, slicing, printing and postprocessing.

The first step of 3D printing is to establish a $3 \mathrm{D}$ model in computer. UG, a 3D modeling software is used to design teaching aids. The modeling process is "geometry instancing" that strengthens students' sense of the space about stereo models[4]. The modeling process is as shown in Fig. 3.

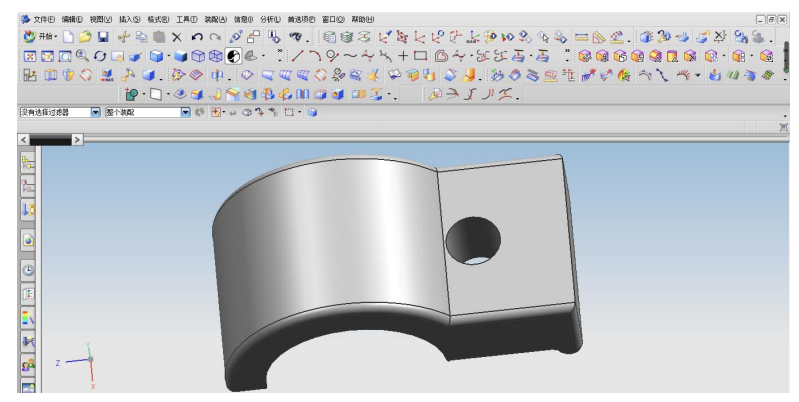

Fig. 3. Modeling process 
The second step is 3D model slicing, which means importing the STL files of 3D model into slice software to slice the model. In the slicing process, students can learn about that 3D stereo models are divided into several overlapping layers. This process also helps students establish their sense of space about stereo models. 3D model slicing in Fig. 4.
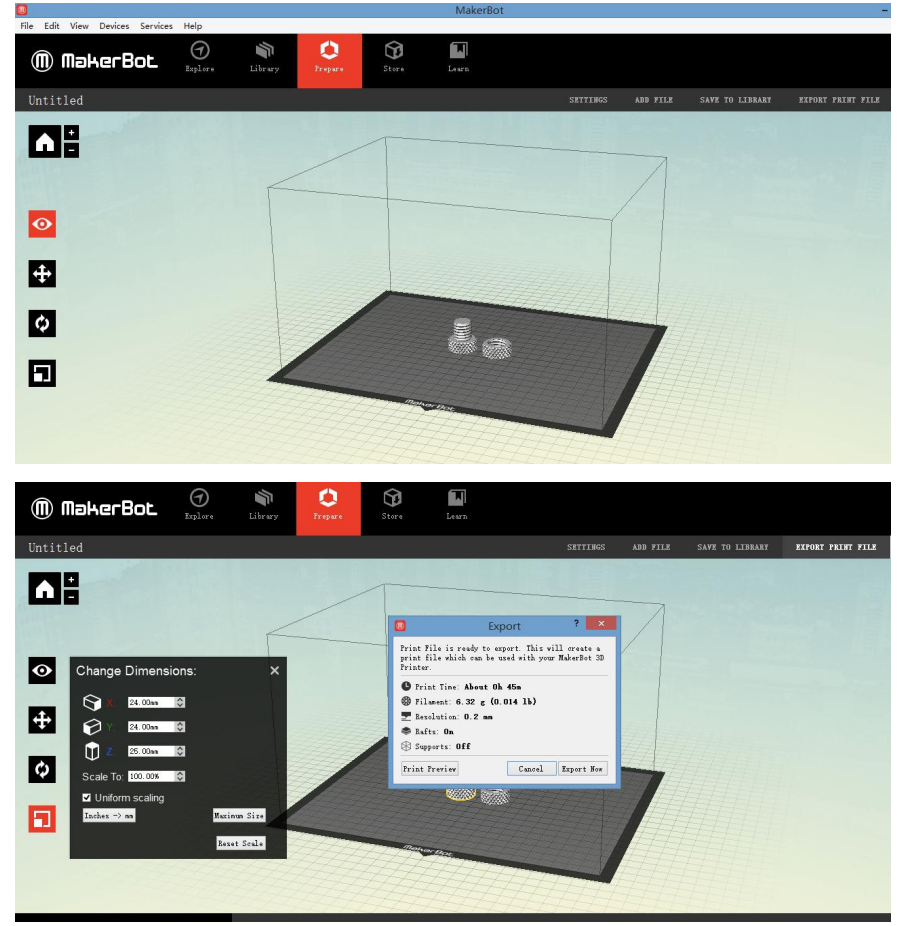

Fig. 4. 3D model slicing

The third step is to load the codes generated by slicing into 3D printer. Once loaded, 3D printer can print work pieces by layer according to the preset program. As a kind of AM technology, 3D printing overlaps materials layer by layer in the modeling process. By observing the molding process, students transform the $2 \mathrm{D}$ plane figure in their mind into $3 \mathrm{D}$ structure. This way, the difficulty to transform plane figures into $3 \mathrm{D}$ figures is significantly simplified in the mechanical drawing study process. Model forming process in Fig. 5.

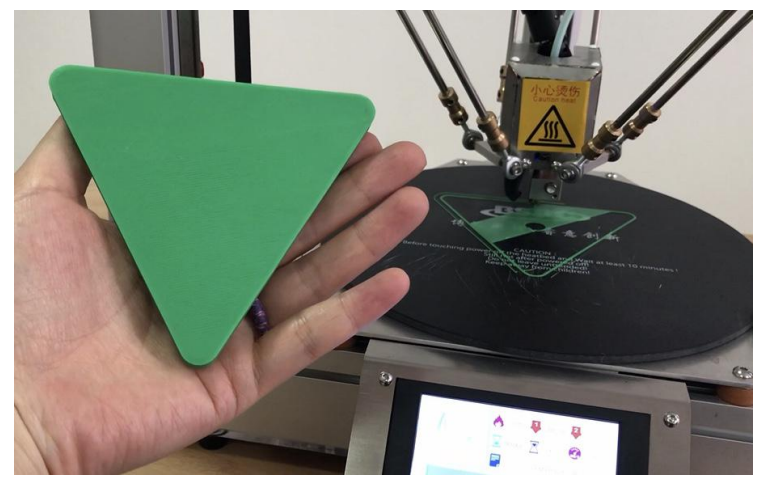

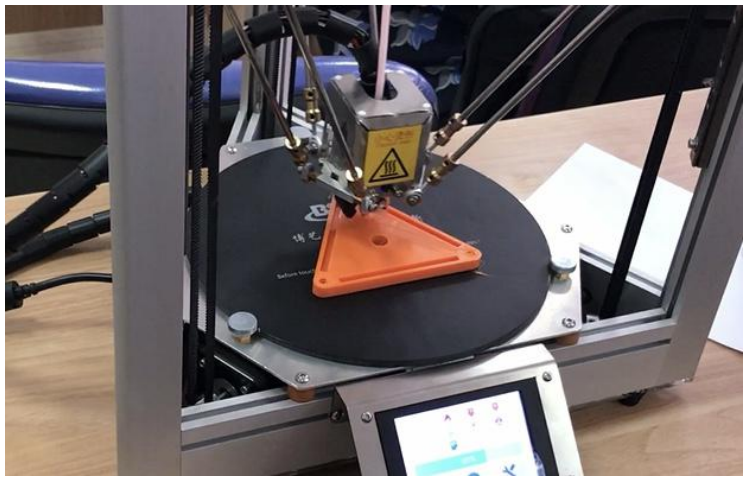

Fig. 5. Model forming process

3D printing technology can quickly print the model parts required by students in the course of drawing class and all parts designed by themselves, students can make new and complicated equipment almost without leaving home. A 3D printer can meet the design needs of 20 to 30 students, students no longer need to design through the traditional machine tools, tools, fixtures to complete, this reduces the processing waiting time for students, also easy to view the rationality of the design, it also saves huge processing costs. At the same time, the development of 3D printers integrates a great deal of knowledge in the fields of machinery, electronics and computers, most of its parts can be printed themselves, students can also design, modify and optimize the parts themselves when printing models with $3 \mathrm{D}$ printers, apply the theoretical knowledge learned in class to practice, improve students'design ability and practical ability [5] [6].

The combination of 3D model printing process and Mechanical Drawing class attracts more interests of students, livens up class atmosphere and makes the class not boring any longer to students.

The following part is the final result of the teaching aids for Mechanical Drawing, as shown in Fig. 6.
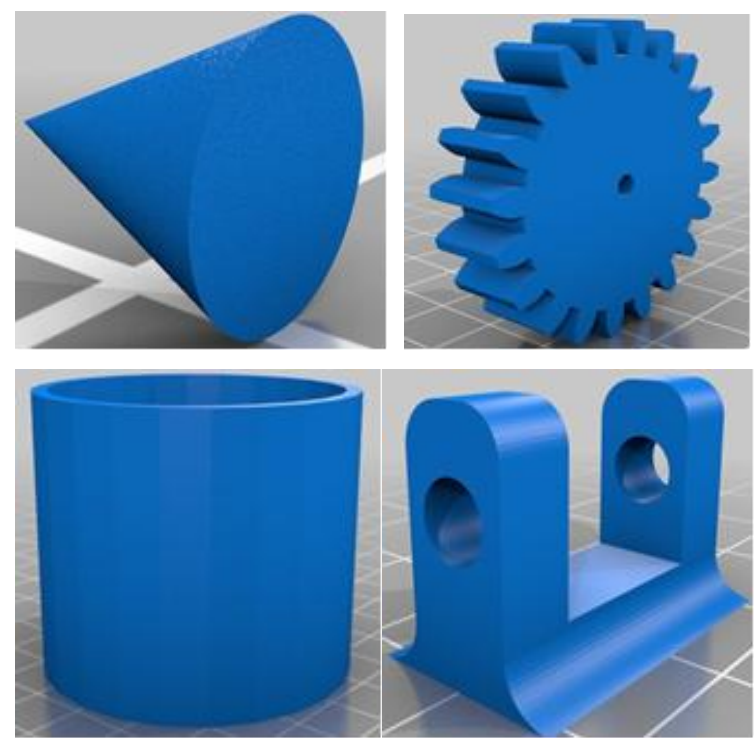

Fig. 6. Teaching aids 


\section{CONCLUSION}

In a word, the application of 3D printing teaching aids in Mechanical Drawing course teaching not only provides the physical 3D teaching aids necessary for the class, but also enriches teaching aid resources and saving teaching aid cost. The teaching aids presented in class can stimulate students' study interests, widen their thinking space and improve their spatial imagination so that they can master how to read and draw mechanical drawings quickly; and enhance study results and teaching efficiency. For its success in improving teaching effect and stimulating student's learning passion and creativity, it plays a significant role in practical teaching[7].

\section{REFERENCES}

[1] J.Zheng Hailie, Zhou Shouming, Xie Yuxia and Liu Xiaojun. Design and Manufacturing based on 3D Printing Teaching Aids, vol. 32. Mechanical Research \& Application, 2019, pp.126-127+131.(In Chinese)
[2] J. Sun Wenzhu, Qu Jianling, Gao Feng, Yuan Tao and Guo Chaoran. Application of 3D Printing Technology in the Teaching of Aeronautical Instrumentation Class. Education Teaching Forum, 2018, pp.92-94. (In Chinese)

[3] J. ZHANG Xiang, The Role of Object and Model in The Teaching of Mechanical Drawing, Success (Education), 2007, pp.192. (In Chinese)

[4] J. HU Yanan, CHEN Xin and ZHAO Jinwen. The application of 3D printing technology in teaching AIDS production and teaching in the nursing department. Contemporary Education Research and Teaching Practice, 2017, pp.35. (In Chinese)

[5] J. LI Huiling and LEI Fang. Discussion on the application of 3D printing technology in mechanical teaching. Industrial \& Science Tribune, 2019, pp.162-163. (In Chinese)

[6] J. SHI Hongsong. The application of 3D printing technology in the teaching of mechanical design and principle. China Computer \& Communication, 2018, pp.239-240. (In Chinese)

[7] J. Kuang Xin. Application of 3D Printing Technology in the Teaching Aid Manufacturing and Teaching. China Southern Agricultural Machinery 2015, pp.64. (In Chinese) 